Итерационная процедура решения системы уравнений (1) при ширине заготовки D = 100 мм

\begin{tabular}{|c|c|c|c|c|c|c|}
\hline № итерации & 0 & 1 & 1 & 2 & 2 & 3 \\
\hline$\omega_{0}$, мм & 1,800 & 1,972 & 1,972 & 1,996 & 1,996 & 2,002 \\
\hline$\varphi_{0}$, мм & $-0,1413$ & $-0,1413$ & $-0,1453$ & $-0,1453$ & $-0,1458$ & $-0,1458$ \\
\hline$\varphi_{\mathrm{m}+1}$, рад & 0,026684 & 0,000013 & 0,003537 & 0,000498 & 0,000963 & 0,000148 \\
\hline $\mathrm{P}, \mathrm{H}$ & $-11,7$ & 2808,1 & $-127,0$ & 296,4 & $-75,7$ & 30,1 \\
\hline
\end{tabular}

Таблица 3

Рассчитанные в 3-й итерации значения меридиональной кривизны заготовки, осредненные в пределах элемента при ширине заготовки $D=100$ мм

\begin{tabular}{|c|c|c|c|}
\hline № элемента & Кривизна $\mathrm{k}_{1}, \mathbf{M}^{-1}$ & № элемента & ${\text { Кривизна } \mathrm{k}_{1}, \mathbf{M}^{-1}}^{-1}$ \\
\hline 1 & $-4,98$ & 11 & $-2,71$ \\
\hline 2 & $-4,91$ & 12 & $-2,43$ \\
\hline 3 & $-4,76$ & 13 & $-2,16$ \\
\hline 4 & $-4,57$ & 14 & $-1,91$ \\
\hline 5 & $-4,34$ & 15 & $-1,69$ \\
\hline 6 & $-4,09$ & 16 & $-1,33$ \\
\hline 7 & $-3,82$ & 17 & $-1,20$ \\
\hline 8 & $-3,55$ & 18 & $-1,11$ \\
\hline 9 & $-3,27$ & 10 & $-1,07$ \\
\hline
\end{tabular}

Выводы. При численном расчете искажения предусматривать проверку сходимости вычислений корней системы уравнений (1). Если вычисления расходятся, итерационная процедура изменяется: параметр $\varphi_{0}$ определяется из 2-го уравнения (1), а параметр $\omega_{0}-$ из 1-го уравнения (1).

Определение деформирования исходного прямоугольного сечения профильных заготовок при изготовлении гибкой элементов конструкций изделий аэрокосмической техники типа шпангоут позволяет повысить точность технологических расчётов и учесть это деформирование для обеспечения стыковочных диаметральных размеров.

\section{Библиографические ссылки}

1. Хилл Р. Математическая теория пластичности. Москва : Изд-во ГИТТЛ, 1956. $407 \mathrm{c}$.

2. Власов В.3. Общая теория оболочек и ее применение в технике. Избранные трудыл. Москва : Изд-во АН СССР, 1962. Т. $1.528 \mathrm{c}$.

3. Калиткин Н.Н. Численные методы. Москва : Наука, 1978. 512 с.

Надійшла до редколегії 21.05.2018 p

УДК 621.454.2.046.2

\title{
ЭКСПЕРИМЕНТАЛЬНОЕ ПОДТВЕРЖДЕНИЕ РАБОТОСПОСОБНОСТИ КАПИЛЛЯРНОГО ЗАБОРНОГО УСТРОЙСТВА (СЕТЧАТОГО РАЗДЕЛИТЕЛЯ) ПРИ ПРОГРАММНОМ РАЗВОРОТЕ
}

\author{
И.В. Седых, Д.Э. Смоленский, Д.С. Назаренко
}

ГП «КБ «Южное» им М.К. Янгеля», ул. Криворожская, 3, г. Днепр, 49010, Украина, e-mail:bers_1@ukr.net

Однісю 3 проблем забезпечення групового виведення космічних апаратів с забезпечення повторного запуску маршового двигуна для переходу на іншу орбіту, після відділення першого апарату. При програмному розвертанні ступінь відчуває прискорення різноманітного напрямку, що призводить до відтоку компонента палива від сіткового роздільника. Це, в свою чергу, призводить до оголення 
сіткового роздільника та проникнення газу під нього, що може призвести до зриву запуску маршового двигуна. Зважаючи на складність гідродинамічних процесів, що протікають у баках, необхідне експериментальне підтвердження вибраних при проектуванні параметрів сіткових роздільників.

В даній роботі описано методи визначення модельних умов (вибір масштабу дослідної конструкції, виду модельної рідини, величини прискорення та інше), дано опис стенду, розробленого спеціально для цих випробувань, а також приведено результати експериментального підтвердження працездатності капілярного забірного пристрою при відділенні космічного апарату. Результати робіт підтверджують правильність рішень, прийнятих при розробці капілярних забірних пристроїв.

Ключові слова: капілярний забірний пристрій, програмне розвертання, кінематична модель, стендова база, критерії подібності, прискорення.

One of the problems of providing a group launch of spacecraft is to ensure the re-launch of the propulsion engine for the transition to another orbit, after the separation of the first vehicle. When the spacecraft is separated into a stage, an acceleration is applied directed toward the bottom of the tank and leading to an outflow of the fuel component from the mesh separator. This, in turn, leads to the denudation of the mesh separator and the penetration of gas under it, which can lead to a breakdown of the launch of the engine. In view of the complexity of the hydrodynamic processes taking place in the tanks, experimental confirmation of the mesh separators chosen during the design is required.

In this paper, we describe the methods for determining the model conditions (the choice of the scale of the experimental design, the type of the model fluid, the magnitude of the accelerations, etc.), a description of the stand designed specifically for the test data, and the results of the experimental confirmation of the capillary sampling device performance in the separation of the spacecraft. The results of the performed works confirm the correctness of the decisions made in the development of capillary sampling devices.

Keywords: acquisition propellant device, program turn, kinematic model, test stand base, similarity criterion, acceleration.

Одной из проблем обеспечения группового выведения космических аппаратов является обеспечение повторного запуска маршевого двигателя для перехода на другую орбиту, после отделения первого аппарата. При программном развороте ступень испытывает ускорение различного направления, что приводит к оттоку компонента топлива от сетчатого разделителя. Это, в свою очередь, приводит к оголению сетчатого разделителя и проникновению газа под него, что может привести к срыву запуска маршевого двигателя. Ввиду сложности протекающих в баках гидродинамических процессов требуется экспериментальное подтверждение выбранных при проектировании параметров сетчатых разделителей.

В данной работе описаны методы определения модельных условий (выбор масштаба опытной конструкции, вида модельной жидкости, величины ускорений и т.д.), дано описание стенда и приведены результаты экспериментального подтверждения работоспособности капиллярного заборного устройства при программном развороте. Результаты проведенных работ подтверждают правильность решений, принятых при разработке капиллярных заборных устройств.

Ключевые слова: капиллярное заборное устройство, программный разворот, кинематическая модель, стендовая база, критерии подобия, ускорение.

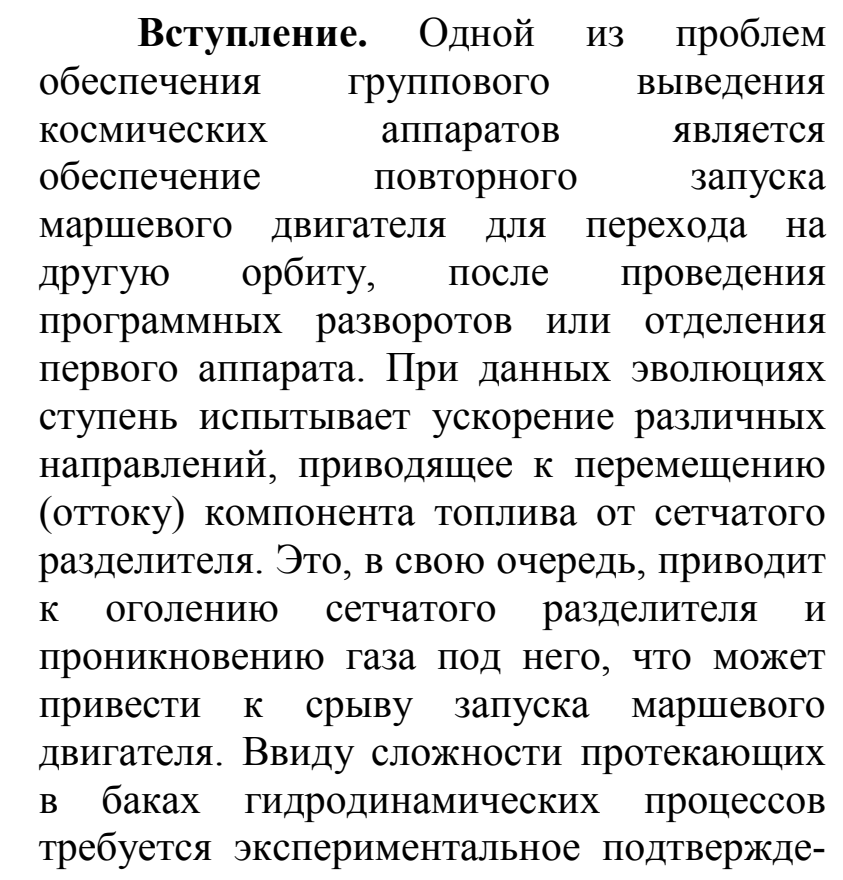

ние выбранных при проектировании параметров сетчатых разделителей. Постановка задачи. При программном развороте ступени тяга от рулевых двигателей создает продольное ускорение и момент вращения относительно центра масс, которые приводят к сложному пространственному движению ступени. Это, в свою очередь, может привести к оттоку компонентов топлива от расходной магистрали и, как следствие, к проникновению газа в расходную магистраль.

Для удержания части компонентов топлива у входа в расходную магистраль системы питания маршевого двигателя до его последнего включения без попадания свободных газовых включений применяют 
капиллярный стабилизатор. Конструкция капиллярного стабилизатора аналогична описанной в [4] (рис. 1).

Если удерживающая сила сетки капиллярного стабилизатора меньше инерционных сил перемещения компонента топлива, происходит попадание газа под сетчатый фазоразделитель, а затем в расходную магистраль, что приведет к срыву запуска маршевого двигателя.

Для подтверждения работоспособности капиллярного стабилизатора при программном развороте необходимо проведение наземной экспериментальной отработки.

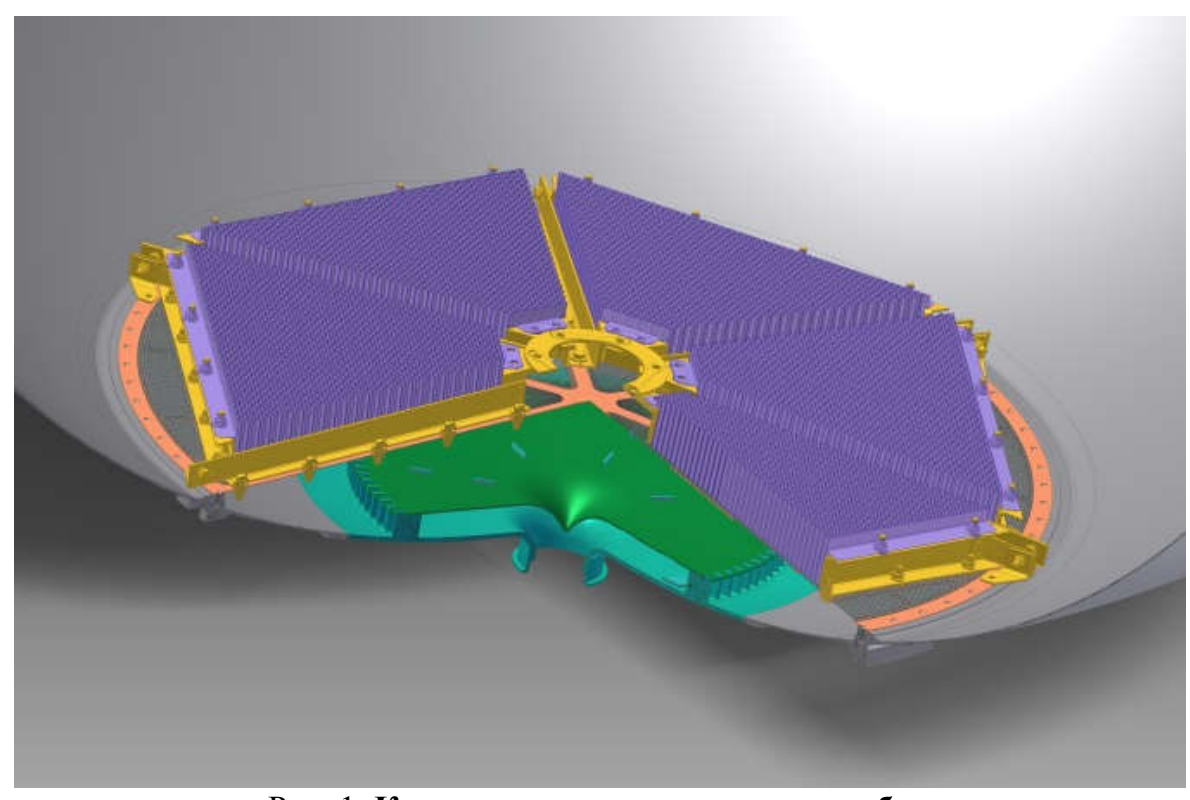

Рис. 1. Конструкция капиллярного стабилизатора

Методика моделирования натурных условий. Моделирование гидродинамических процессов, протекающих в баках ракет при программном развороте, чрезвычайно сложно, не может быть в полной мере описано математическими методами и требует подтверждения расчетных результатов экспериментальными исследованиями. При этом различия между натурными условиями космического полета и условиями, воспроизводящимися при земном тяготении, требуют соблюдения равенства некоторых безразмерных комплексов, характеризующих модельные и натурные параметры. Такие безразмерные комплексы носят названия критериев подобия, а к параметрам относят конструктивные параметры баков, физико-химические параметры топлива, кинематические параметры и внешние воздействующие факторы.

Для моделирования гидродинамических процессов, происходящих в баке при отделении космического аппарата, необходимо выдержать равенство модельных и натурных критериев Рейнольдса Re, Бонда Bo, гомохронности Но и краевых углов $\theta$ :

$$
\begin{gathered}
W e=\frac{w_{H}^{2} l_{H}}{\beta_{H}}=\frac{w_{M}^{2} l_{M}}{\beta_{M}}, \\
\operatorname{Re}=\frac{w_{H} l_{H}}{v_{H}}=\frac{w_{M} l_{M}}{v_{M}}, \\
H o=\frac{a_{H} \tau_{H}^{2}}{l_{H}}=\frac{a_{M} \tau_{M}^{2}}{l_{M}},
\end{gathered}
$$

где $\mathrm{w}$ - характерная скорость движения жидкого компонента топлива;

а - ускорение бака;

1 - характерный линейный размер;

$v$ - кинематическая вязкость жидкости;

$\beta$-кинематический коэффициент поверх-

ностного натяжения $\left(\beta=\frac{\sigma}{\rho}\right)$;
$\rho$ - плотность;

$\sigma-$ поверхностное натяжение;

$\tau$ - время действия ускорения.

Для гидродинамического подобия процессов в модели и в натурном баке необходимо равенство краевых углов, критериев Вебера Weн=Weм, Рейнольдса 
$\mathrm{ReH}=\mathrm{Reм}$ и гомохромности Нон=Ном, где индекс «н» - означает натурные величины, а индекс «м» - модельные:

$$
\left\{\begin{array}{l}
\frac{\mathrm{W}_{\mathrm{H}}^{2} \cdot 1_{\mathrm{H}}}{\beta_{\mathrm{H}}}=\frac{\mathrm{W}_{\mathrm{M}}^{2} \cdot 1_{\mathrm{M}}}{\beta_{\mathrm{M}}}, \\
\frac{\mathrm{W}_{\mathrm{H}} \cdot 1_{\mathrm{H}}}{\mathrm{V}_{\mathrm{H}}}=\frac{\mathrm{W}_{\mathrm{M}} \cdot 1_{\mathrm{M}}}{\mathrm{V}_{\mathrm{M}}}, \\
\frac{\mathrm{W}_{\mathrm{H}} \cdot \tau_{\mathrm{H}}}{1_{\mathrm{H}}}=\frac{\mathrm{W}_{\mathrm{M}} \cdot \tau_{\mathrm{M}}}{1_{M}},
\end{array}\right.
$$

Равенство краевых

углов обеспечивается выбором модельных жидкостей. У применяемых на ракетахносителях компонентов топлива краевой угол близок к нулю (при контакте со сплавами АМг6 и 0,3Х18Н10T).

Выдержать одновременно соотношения по $\mathrm{We}$ и $\mathrm{Re}$ для применяемых компонентов и модельных жидкостей невозможно. Поэтому моделирование по числу Рейнольдса не выдерживается, а при проведении испытаний изменением масштабного фактора должно быть подтверждено, что число Re лежит в зоне автомодельности.

Заменяя $\mathrm{w}=\mathrm{a} \cdot \tau$, где $\mathrm{a}-$ ускорение, и исключая Re, преобразуем систему к виду:

$$
\left\{\begin{aligned}
\frac{\left(\mathrm{a}_{\mathrm{H}} \cdot \tau_{\mathrm{H}}\right)^{2} \cdot 1_{\mathrm{H}}}{\beta_{\mathrm{H}}} & =\frac{\left(\mathrm{a}_{\mathrm{M}} \cdot \tau_{\mathrm{M}}\right)^{2} \cdot 1_{\mathrm{M}}}{\beta_{\mathrm{M}}} \\
\frac{\mathrm{a}_{\mathrm{H}} \cdot \tau_{\mathrm{H}}^{2}}{1_{\mathrm{H}}} & =\frac{\mathrm{a}_{\mathrm{M}} \cdot \tau_{\mathrm{M}}^{2}}{1_{\mathrm{M}}}
\end{aligned}\right.
$$

Решая систему уравнений, получаем следующие соотношения:

$$
\begin{aligned}
& \frac{a_{M}}{a_{н}}=\frac{\beta_{M}}{\beta_{H}} \cdot\left(\frac{1_{\text {H }}}{1_{M}}\right)^{2}, \\
& \frac{\tau_{M}}{\tau_{\text {н }}}=\sqrt{\frac{\beta_{H}}{\beta_{M}} \cdot\left(\frac{1_{M}}{1_{H}}\right)^{3}}
\end{aligned}
$$

Откуда получаем зависимость для определения модельного ускорения и времени его действия:

$$
\mathrm{a}_{\mathrm{M}}=\mathrm{a}_{\mathrm{H}} \cdot \frac{\beta_{\mathrm{M}}}{\beta_{\text {н }}} \cdot\left(\frac{1_{\text {н }}}{1_{\mathrm{M}}}\right)^{2},
$$

$$
\tau_{\text {м }}=\tau_{\text {н }} \cdot \sqrt{\frac{\beta_{\text {н }}}{\beta_{\text {м }}} \cdot\left(\frac{1_{\text {м }}}{1_{\text {н }}}\right)^{3}},
$$

Задавшись размерами модельной емкости (масштаб 1 - 1:3; масштаб 2 - 1:5) и подставив натурные параметры в соотношения, определяем модельные значения продольного ускорения и времени его действия для двух расчетных случаев веса космического аппарата 650 кгс и 5300 кгс.

Натурные и модельные боковые ускорения и время их действия приведены в табл. 1.

Стендовая база. Для проведения экспериментального подтверждения работоспособности капиллярного заборного устройства при програмном развороте использовался стенд невесомости (рис. 2).

Стенд невесомости обеспечивает время свободного падения до 2,55 с.

При испытаниях программный разворот имитировался с помощью газореактивной системы кинематической модели. Дальнейшее свободное падение кинематической модели имитировало состояние невесомости после программного разворота.

\section{Проведение испытаний.} соответствии с программой испытаний экспериментальная отработка проводилась двумя этапами: предварительные испытания; приемочные испытания. Предварительные испытания проводились в следующем порядке:

1) перед началом испытания проводилась заправка модельной емкости рабочей жидкостью от стендовых источников. После заправки модельной емкости с помощью тестового видеоизмерения определялся уровень модельной жидкости в емкости и отсутствие газовых включений под капиллярным стабилизатором. Контроль заполнения проводился визуально;

2) КМ подвешивалась в подвесном устройстве и после полного ее успокоения производился сброс КМ с высоты 32 м;

3) после разрыва связей между стендом и КМ включалась ГРС; 
Натурные и модельные боковые ускорения и их длительность

\begin{tabular}{|c|c|c|c|c|c|c|}
\hline & \multicolumn{3}{|c|}{ До отделения КА } & \multicolumn{3}{|c|}{ После отделения КА } \\
\hline & \multirow{2}{*}{ натурное } & \multicolumn{2}{|c|}{ модельное } & \multirow{2}{*}{ натурное } & \multicolumn{2}{|c|}{ модельное } \\
\hline & & РБР & Нафтил & & РБР & Нафтил \\
\hline $\mathbf{a}_{\overline{0}}, \mathbf{M} / \mathbf{c} 2$ & 0,00248 & 0,08 & $\mathbf{0 , 1 1}$ & 0,059 & 2,11 & 2,77 \\
\hline$\tau, \mathbf{c}$ & 24 & $\mathbf{1 , 8 1}$ & $\mathbf{1 , 5 8}$ & 2,6 & 0,2 & $\mathbf{0 , 1 7}$ \\
\hline
\end{tabular}

Замок подвеса KM

Кинематическая модель

Площадка

обслуживания $\mathrm{KM}$

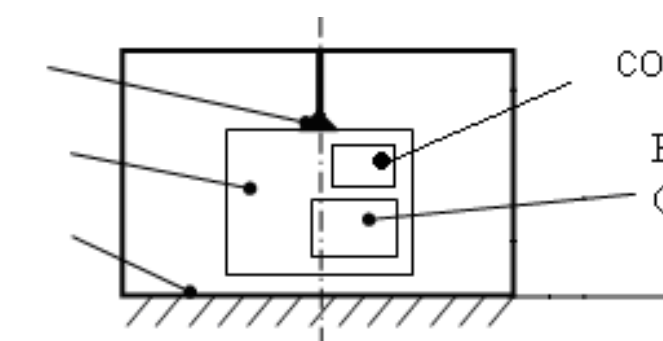

$\mathrm{con}$

Бортовой сегмент

СУИКМ

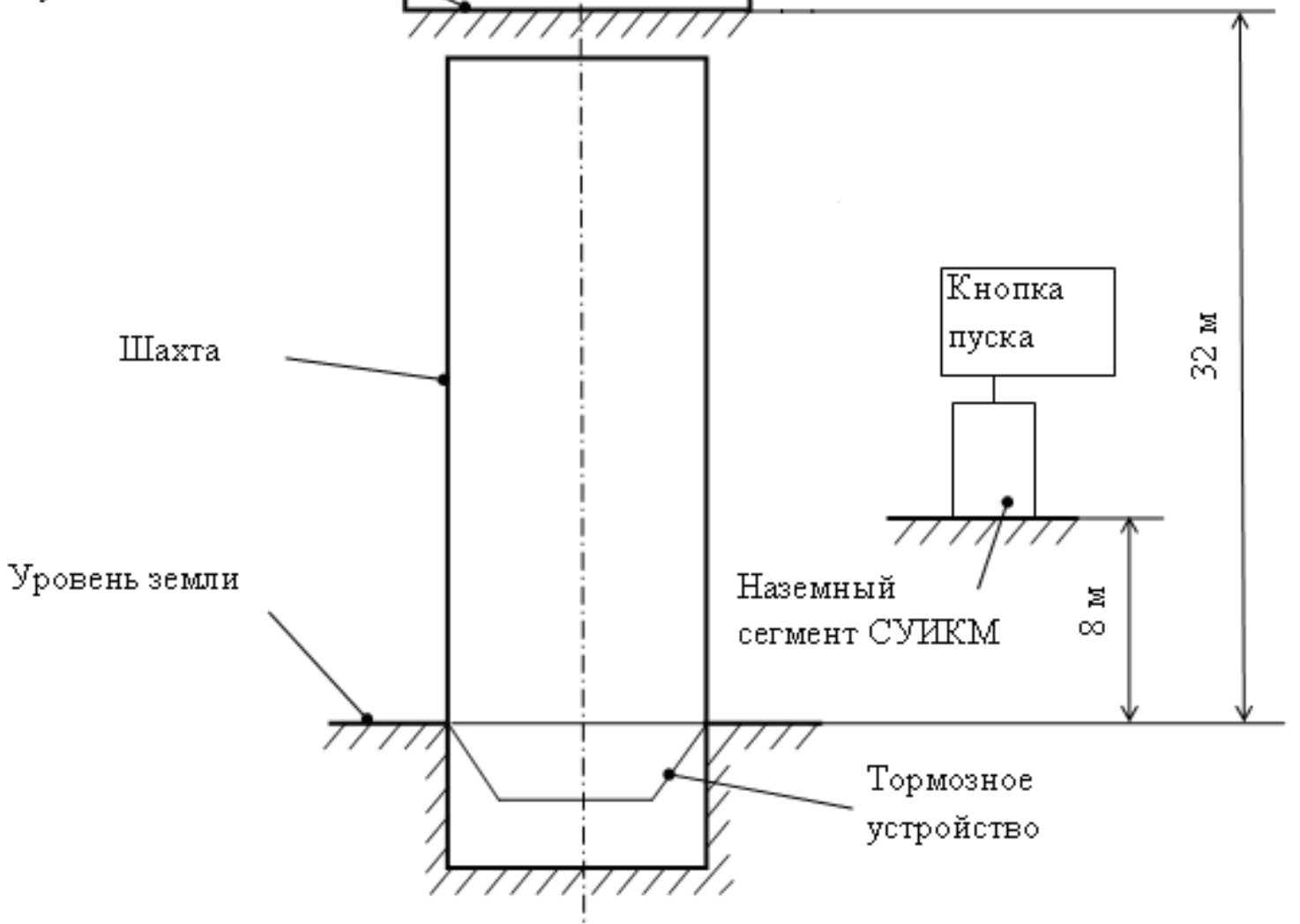

Рис. 2. Схема стенда невесомости

4) после торможения КМ в тормозном устройстве производилось снятие данных с последующей обработкой.

Фиксация непроникновения газа под сетчатый фазоразделитель проводилась визуально по кадрам видеосъемки.

Испытания проводились для моделирования условий полета после отделения космического аппарата:

- двух значений ускорения: номинального (вариант А) и в 2 раза превышающего его (вариант Б); нафтил);
- одного типа сетки капиллярного стабилизатора: сетки 0080x0,055.

Всего было проведено 96 испытаний (в том числе и отладочные), из них 70 зачетных.

Результаты испытаний. Типовой уровень заправки жидкостью модельной емкости (рис. 3).

Положение модельной жидкости в емкости в момент окончания действия ускорения (зафиксирован прорыв газа) (рис. 4).

Типовое положение модельной жидкости в емкости в момент окончания действия ускорения (рис. 5 и 6). 


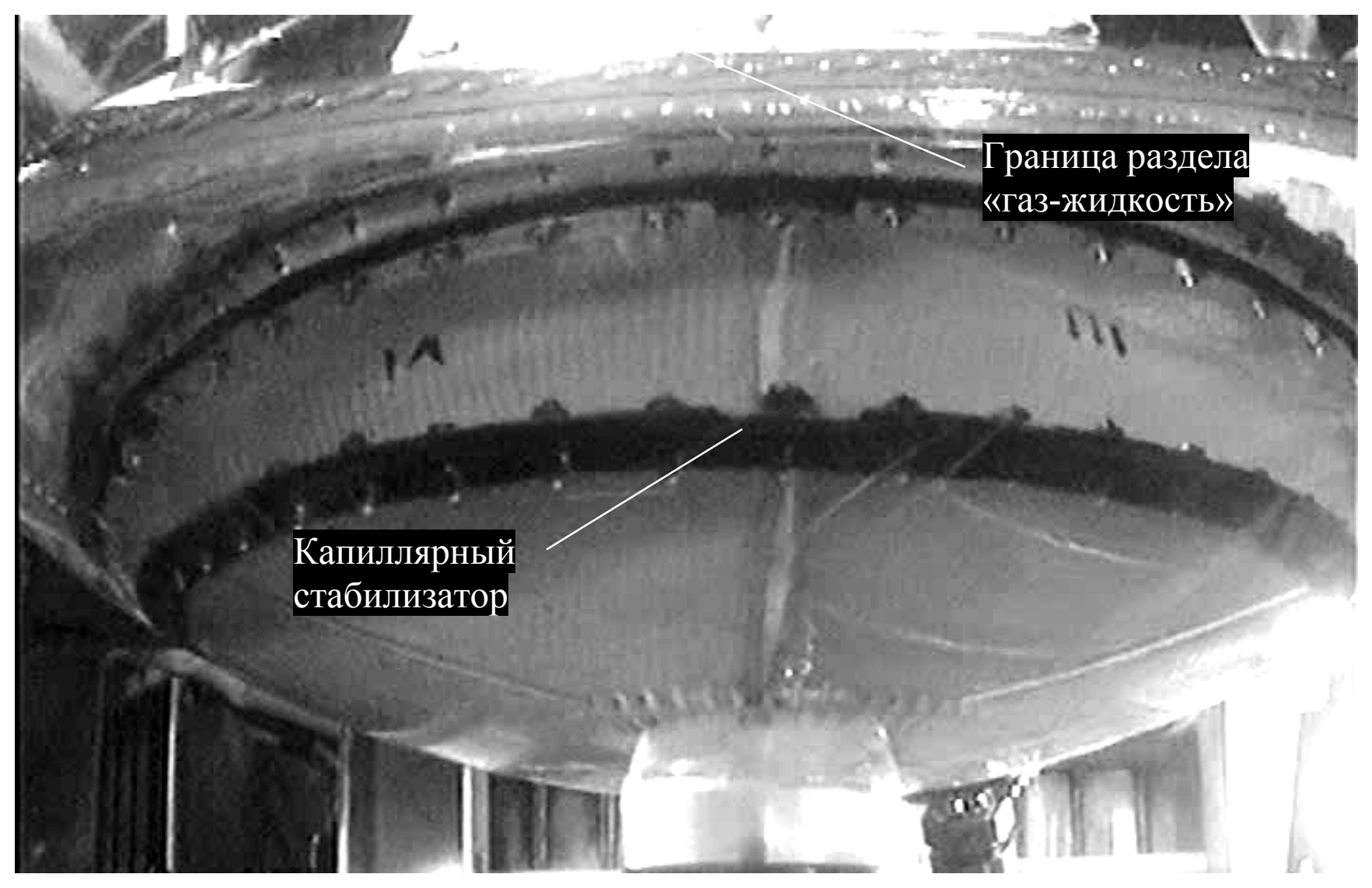

Рис. 3. Положение модельной жидкости при заправке

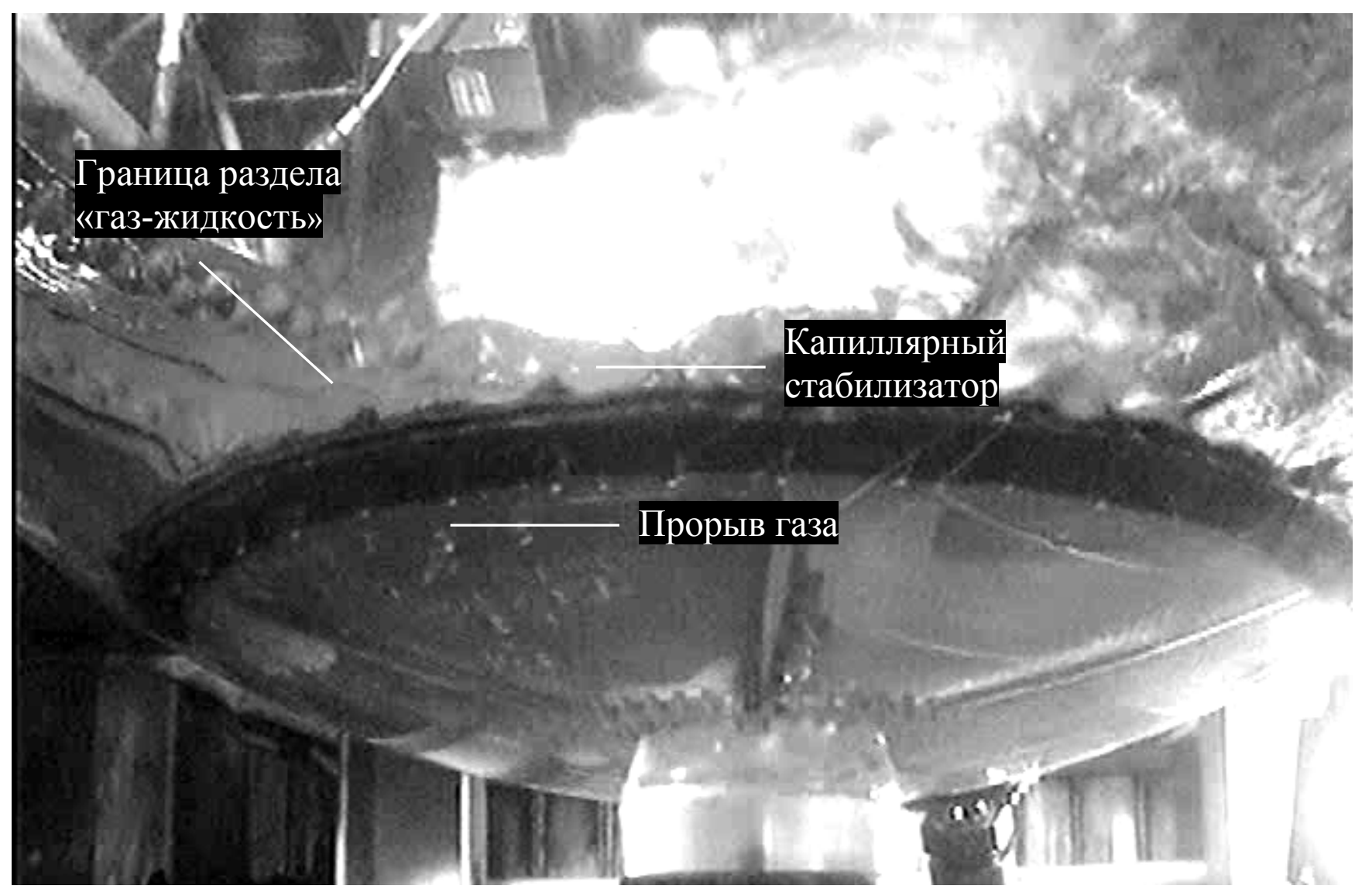

Рис. 4. Положение жидкости в момент окончания действия продольного ускорения (зафиксирован прорыв газа под стабилизатор) 


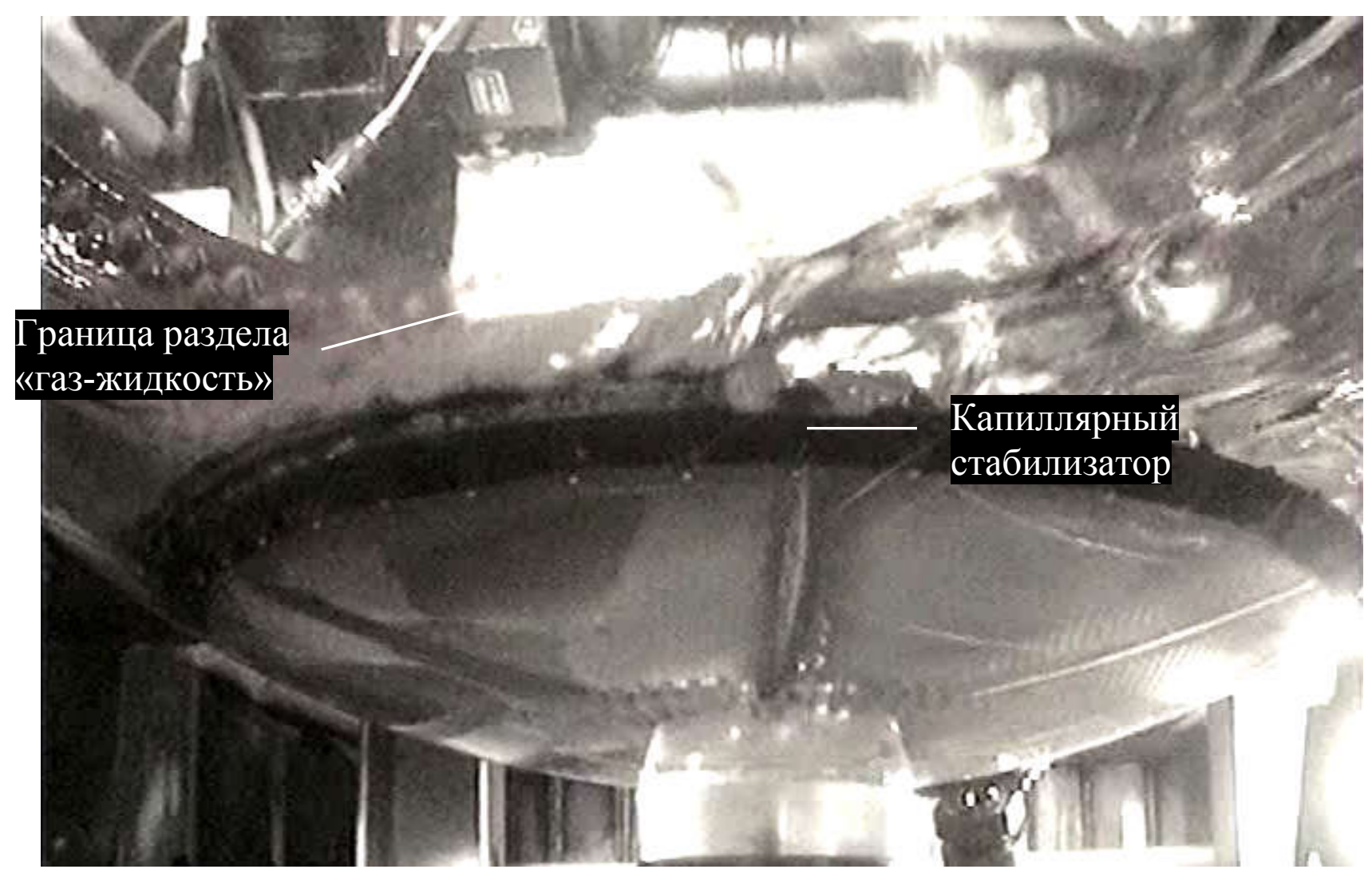

Рис. 5. Положение жидкости в момент окончания действия продольного ускорения (прорыв газа под стабилизатор не зафиксирован)

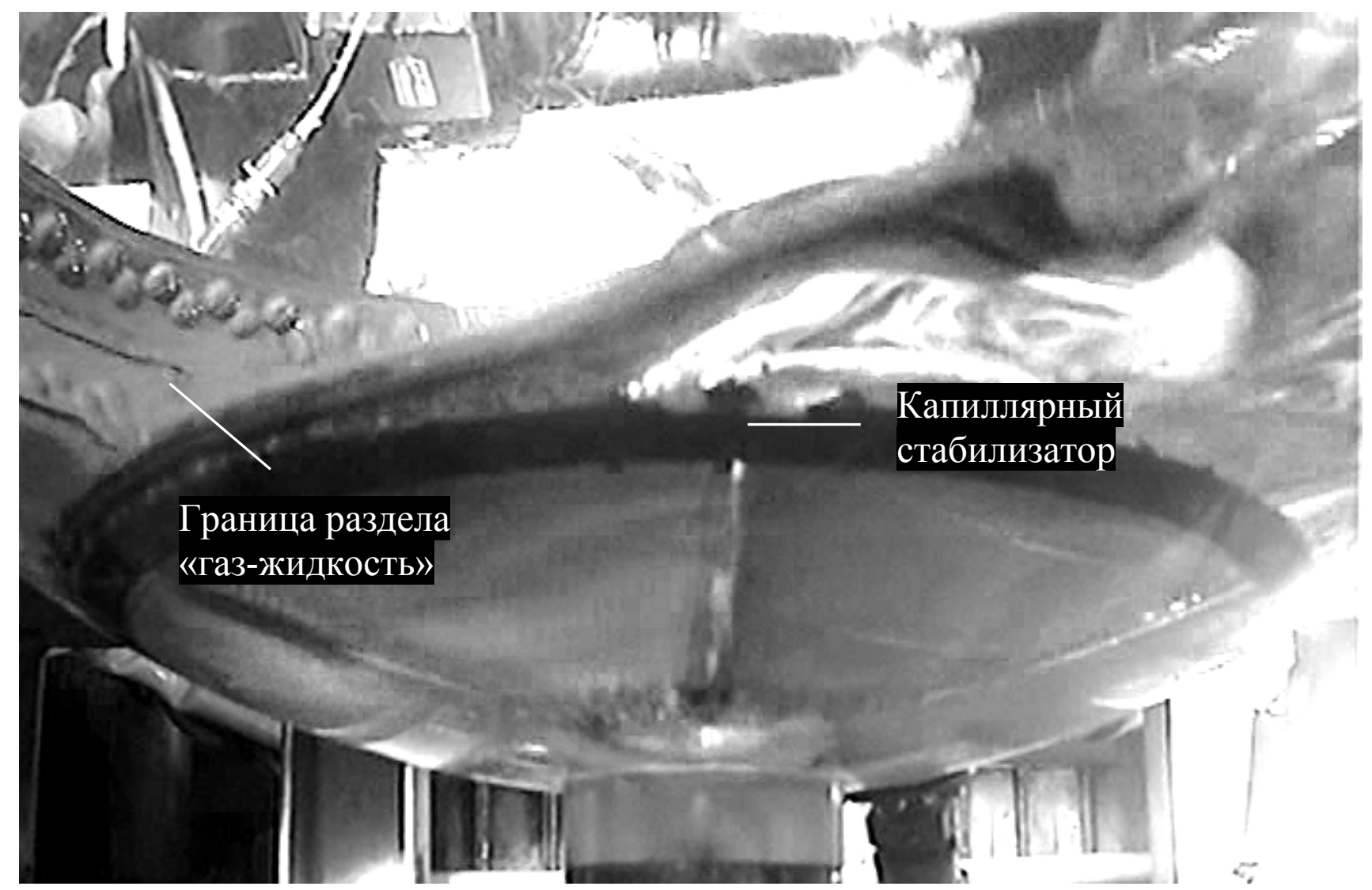

Рис. 6. Положение жидкости в момент окончания действия продольного ускорения (прорыв газа под стабилизатор не зафиксирован) 
Анализ полученных результатов. При испытаниях капиллярного стабилизатора на рабочей жидкости РБР отсутствие прорыва газа под сетку достигнуто при ускорении, в $\sim 1,5$ раза превышающем эквивалентное ускорение 3й ступени при программном развороте на участке полета после отделения КА.

При испытаниях капиллярного стабилизатора на рабочей жидкости керосин отсутствие прорыва газа под сетку достигнуто при ускорении, эквивалентном ускорению 3-й ступени при программном развороте на участке полета после отделения КА.

Анализ поведения границы раздела фаз «газ-жидкость» во время действия модельного ускорения и до момента торможения кинематической модели показал, что в процессе испытаний граница раздела фаз «газ-жидкость» находилась над капиллярным стабилизатором для всех видов испытаний.

Видеоизмерения показали схожесть внутрибаковых процессов при применении различных модельных жидкостей - РБР и нафтила, что подтверждает правомерность исключения числа $\operatorname{Re}$ из критериев подобия.

Пересчет модельных параметров на натурные. В соответствии с методикой моделирования модельные параметры не равны натурным, а определяются в соответствии с критериями подобия. Для анализа условий нагружений сетчатого разделителя при полете ступени с учетом результатов испытаний необходимо произвести пересчет полученных модельных ускорений и времени его действия на натурные.

Пересчет модельного ускорения и времени в натурные осуществляется по формулам:

$$
\begin{gathered}
a_{\text {н }}=\frac{a_{\text {м }}}{\frac{\beta_{\mathrm{M}}}{\beta_{\text {н }}} \cdot\left(\frac{1_{\text {H }}}{1_{\mathrm{M}}}\right)^{2}} \\
\tau_{\mathrm{H}}=\frac{\tau_{\mathrm{M}}}{\sqrt{\frac{\beta_{\mathrm{H}}}{\beta_{\mathrm{M}}} \cdot\left(\frac{1_{\mathrm{M}}}{1_{\text {н }}}\right)^{3}}}
\end{gathered}
$$

Боковое ускорение на участке полета после отделения КА составляет $0,059 \mathrm{~m} / \mathrm{c}^{2}$. Реализованные экспериментальные максимальные ускорения, пересчитанные на натурные условия, составляют от $0,0543 \mathrm{M} / \mathrm{c}^{2}$ до $0,118 \mathrm{~m} / \mathrm{c}^{2}$.

Выводы. При исследовании было осуществлено моделирование по числу Вебера и числу гомохронности, в рассматриваемом диапазоне параметров было подтверждено, что по числу Рейнольдса имеет место режим автомодельности.

В результате проведения испытаний была достигнута цель экспериментальных работ - подтверждение непроникновения газа сквозь сетку капиллярного стабилизатора заборного устройства окислителя, что подтверждает работоспособность капиллярного заборного устройства при программном развороте:

- для модельной жидкости РБР - при ускорении, в 1,5 раза превышающем эквивалентное ускорение 3-й ступени при программном развороте на участке полета после отделения КА;

- для модельной жидкости керосин при номинальном эквивалентном ускорении 3-й ступени при программном развороте на участке полета после отделения КА.

\section{Библиографические ссылки}

1. Проблемы гидродинамики и теплообмена в условиях невесомости / под ред. Швецовой А.Я., Слянова Е.А. ГОНТИ, 1970. 479 c.

2. Двигательные установки ракет на жидком топливе / под ред. Э. Ринга. Москва : ИЛ, 1966. 404 с.

3. Астронавтика и ракетодинамика. Экспресс-информация. 1986. № 7.

4. Экспериментальное подтверждение работоспособности капиллянного забороного устройства при отделении космического аппарата / И.В. Седых, Д.Э. Смоленский. Механика гироскопических систем. № 33. 2017 г.

Надійшла до редколегії 21.07.2018 p. 